\title{
Kinetics of singlet oxygen sensing using 9-substituted anthracene derivatives
}

\author{
DEVIKA SASIKUMAR, REIKO KOHARA, YUTA TAKANO*, KEN-ICHI YUYAMA and \\ VASUDEVANPILLAI BIJU* (D) \\ Research Institute for Electronic Science and Graduate School of Environmental Science, Hokkaido University, \\ Kita-20, Nishi-10, Sapporo 001-0020, Japan \\ E-mail: tak@es.hokudai.ac.jp; biju@es.hokudai.ac.jp
}

MS received 6 July 2018; revised 30 September 2018; accepted 21 October 2018; published online 2 January 2019

\begin{abstract}
Singlet oxygen $\left({ }^{1} \mathrm{O}_{2}\right)$, the lowest excited-state of molecular oxygen receives great attention in basic research and clinical and industrial settings. Despite several spectroscopic methods available for ${ }^{1} \mathrm{O}_{2}$ sensing, fluorescence sensing receives great attention, for which many fluorogenic sensors based on substituted anthracene are reported. Nonetheless, the roles of substituents on the sensing efficiency, in terms of detection time, remain largely unknown. In this work, we examine the ${ }^{1} \mathrm{O}_{2}$ sensing efficiency of a fluorescence sensor based on a coumarin-anthracene conjugate, which is an electron donor-acceptor dyad, and compare the efficiency with that of 9-methylanthracene. Here, ${ }^{1} \mathrm{O}_{2}$ is generated using the standard photosensitizer Rose Bengal, which is followed by estimation of the rate of reaction of ${ }^{1} \mathrm{O}_{2}$ to the sensor and 9-methylanthracene. The second order reaction rate of the sensor is an order of magnitude less than that of 9-methylanthracene. The lower reactivity of the sensor to ${ }^{1} \mathrm{O}_{2}$ suggests that the roles of substituents, such as electronic interactions, steric interactions and the reactivity of precursor complexes, on sensing efficiency should be carefully considered during construction of fluorogenic molecular sensors.
\end{abstract}

Keywords. Singlet oxygen; fluorescence sensing; photochemistry; athracene; reaction kinetics.

\section{Introduction}

Reactive oxygen species (ROS) receive considerable attention in chemistry and life science. For example, ROS finds applications in synthetic organic chemistry ${ }^{1-3}$ photodynamic therapy, ${ }^{4-6}$ and environmental remediation. ${ }^{7-9}$ Also, ROS, in particular ${ }^{1} \mathrm{O}_{2}$, plays significant roles in cell signaling ${ }^{10-12}$ and oxidative stress-related progression of various diseases. ${ }^{13-15}$ Owing to the above impacts of ${ }^{1} \mathrm{O}_{2}$ in our daily life, detection of ${ }^{1} \mathrm{O}_{2}$ has emerged into an active research subject. ${ }^{19}$ In general, ${ }^{1} \mathrm{O}_{2}$ can be detected by various spectroscopic methods based on electron paramagnetic resonance (ESR), ${ }^{20}$ phosphorescence, ${ }^{21-23}$ fluorescence, ${ }^{24-29}$ and absorption. ${ }^{30}$ Among these methods, fluorescence sensing is widely accepted due to its high sensitivity, simple procedure, and cost-effectiveness. Although there are several highly-selective and sensitive fluorogenic sensors of ${ }^{1} \mathrm{O}_{2}$ reported, correlation of the speed of detection with the structures of sensors needs further attention.

So far, the most promising fluorescence sensors of ${ }^{1} \mathrm{O}_{2}$ are based on anthracene derivatives. ${ }^{24-28}$ For example, Tanaka et al., constructed a ${ }^{1} \mathrm{O}_{2}$ sensor based on a fluorescein derivative conjugated to anthracene. ${ }^{24}$ The fundamental structure of such an electron donoracceptor dyad-based sensor is composed of an oxygen trapping moiety, which is anthracene, and a fluorescence reporter moiety. The sensing probe is in a fluorescence "off" state in the absence of ${ }^{1} \mathrm{O}_{2}$, which is by a dominant photoinduced intramolecular electron transfer (PET) from anthracene to fluorescein. The mechanism of sensing relies on [4+2] cycloaddition reaction of ${ }^{1} \mathrm{O}_{2}$ to anthracene, leading to the formation of a 9,10-endoperoxide. Due to the endoperoxide formation, the photoinduced electron transfer is blocked, uncaging the fluorescence and leading to detection of

\footnotetext{
*For correspondence

\# Dedicated to Professor M. V. George on the occasion of his 90th Birth Anniversary.
} 
${ }^{1} \mathrm{O}_{2}$. Recently, several fluorescence sensors working on the above mechanism are introduced by different research groups. ${ }^{24-28}$ Most of these sensors are based on xanthene derivatives conjugated to anthracene. For example, Kim et al., introduced a ${ }^{1} \mathrm{O}_{2}$ sensor, Si-DMA, which is a silicon-based rhodamine-anthracene conjugate. ${ }^{25}$ This sensor is found stable and promising for NIR fluorescence detection of ${ }^{1} \mathrm{O}_{2}$. Although the above sensors focus on highly-selective and sensitive detection of ${ }^{1} \mathrm{O}_{2}$, the sensing rates are yet to be optimized. Si-DMA is reported to show 18 -fold fluorescence enhancement upon $50 \mathrm{~min}$ irradiation $(510-550 \mathrm{~nm}$ at $\left.0.07 \mathrm{~W} \mathrm{~cm}^{-2}\right)$ of the photosensitizer meso-tetra $(N-$ methyl-4-pyridyl) porphine tetratosylate. On the other hand, another ${ }^{1} \mathrm{O}_{2}$ sensor, Arhus Sensor Green (ASG) was reported to need $60 \mathrm{~min}$ to show the saturated fluorescence response in presence of the sensitizer phenalene-1-one-2-sulfonic acid excited with $420 \mathrm{~nm}$, $3 \mathrm{~mW}$ light. ${ }^{26}$ Meanwhile, commercially available ${ }^{1} \mathrm{O}_{2}$ sensor, the Singlet Oxygen Sensor Green (SOSG), ${ }^{27}$ can detect ${ }^{1} \mathrm{O}_{2}$ within $10 \mathrm{~min}$ photosensitization of tetrakis (4-carboxyphenyl) porphyrin at $2.8 \mathrm{~W} \mathrm{~cm}^{-2}(532 \mathrm{~nm}){ }^{28}$ Despite this advantage of SOSG, it is unstable under visible light because of self-sensitized ${ }^{1} \mathrm{O}_{2}$ generation and the subsequent oxidation of the sensor. In other words, SOSG cannot be used for the quantitative detection of ${ }^{1} \mathrm{O}_{2}$. This instability of SOSG guided us into a stable ${ }^{1} \mathrm{O}_{2}$ sensor based on a coumarin-anthracene conjugate (1). ${ }^{28}$ Even though the fluorescence sensitivity, stability, and spectral responses of these sensors are well explored, the relations of ${ }^{1} \mathrm{O}_{2}$ detection rate with the structural features of sensors remain undisclosed. In other words, investigation and optimization of the role of substituents on the rate of ${ }^{1} \mathrm{O}_{2}$ sensing need further attention.

In this work, we discuss the rates of ${ }^{1} \mathrm{O}_{2}$ detection using two 9-substituted anthracenes. We compare the ${ }^{1} \mathrm{O}_{2}$ sensing rate of sensor $\mathbf{1}$ with that of 9methylanthracene (2) by steady-state absorption and fluorescence measurements. We monitored the absorption and fluorescence spectra during the reaction of $\mathbf{1}$ or 2 with ${ }^{1} \mathrm{O}_{2}$ generated by photosensitization of Rose Bengal (RB). With time under photosensitization of RB, 1 shows an enhanced fluorogenic response, but 2 responds with depletion in fluorescence. The rates of ${ }^{1} \mathrm{O}_{2}$ sensing of $\mathbf{1}$ and $\mathbf{2}$ are determined by analyzing their corresponding absorption spectra recorded as a function of time under photosensitization. The rate of reaction of $\mathbf{1}$ with ${ }^{1} \mathrm{O}_{2}$ is found to be an order of magnitude less than that of 2 . The significant difference in the ${ }^{1} \mathrm{O}_{2}$ sensing rates between $\mathbf{1}$ and $\mathbf{2}$ suggests that the substituents on anthracene play an important role on the sensing efficiency. We hypothesize that the relatively bulk coumarin moiety in $\mathbf{1}$ significantly retards the reaction of $\mathbf{1}$ with ${ }^{1} \mathrm{O}_{2}$.

\section{Experimental}

\subsection{Materials}

All the chemicals used in this work were analytical grade and used without further purification. 9-Methylanthracene, Rose Bengal and 7-amino-4-methyl coumarin were obtained from Tokyo chemical industries (TCI, Japan). 9-Chloromethyl anthracene, 1,8-diazabicyclo[5,4,0]undec-7-ene (DBU) and sodium azide were obtained from Merck (USA). Solvents such as dimethylformamide (DMF), acetone, tetrahydrofuran, acetonitrile, and chloroform were obtained from FUJIFILM Wako Pure Chemical Corporation (Japan). 1 was synthesized and characterized according to the reported procedure. ${ }^{28}$

\subsection{Methods}

Absorption and fluorescence spectra were recorded using a UV-Visible spectrophotometer (Evolution 220, ThermoFisher Scientific) and a fluorescence spectrophotometer (Spectrofluorometer FL4500, Hitachi), respectively. For photoirradiation of samples, we used a DPSS $532 \mathrm{~nm}$ Green laser (Shanghai Dream Laser Technology) throughout the experiment.

\subsection{Preparation of model compound $\mathbf{3}$}

7-Amino,4-methyl coumarin (1.753 g, $10 \mathrm{mmol})$ and DBU $(13 \mathrm{~mL})$ were mixed in $15 \mathrm{~mL}$ acetonitrile at room temperature, supplemented with 1-bromopropane $(2.2 \mathrm{~mL})$, and this reaction mixture was stirred at $70^{\circ} \mathrm{C}$. This reaction is schematically presented in Figure $1 \mathrm{~A}$. After $10 \mathrm{~h}$ at this temperature, the reaction mixture was cooled to room temperature, and added excess water, providing a yellow residue. The residue was collected by filtration, washed with water, dissolved in ethyl acetate, dried on anhydrous $\mathrm{Mg}_{2} \mathrm{SO}_{4}$, and purified by column chromatography on silica gel (200 mesh) using a mixture $(1: 4 \mathrm{v} / \mathrm{v})$ of ethyl acetate and toluene as the eluent to provide $1.75 \mathrm{~g}(72 \%) 3 .{ }^{1} \mathrm{H}$ NMR $\left(\mathrm{CDCl}_{3}\right): \delta 7.37$ $7.31(\mathrm{~d}, 1 \mathrm{H}), 6.54-6.48(\mathrm{dd}, 1 \mathrm{H}), 6.45-6.44(\mathrm{~d}, 1 \mathrm{H}), 5.97-5.93$ (s, 1H), 4.43-4.35 (t, 1H), 3.17-3.10 (dd, 2H), 2.36-2.20 (s, $3 \mathrm{H}), 1.72-1.63(\mathrm{tt}, 2 \mathrm{H}), 1.05-0.98(\mathrm{t}, 3 \mathrm{H})$.

\subsection{Samples}

For analyzing the ${ }^{1} \mathrm{O}_{2}$ sensing process, $10 \mu \mathrm{M}$ solution of $\mathbf{1}$ or $10 \mu \mathrm{M}$ solution 2 in DMF was mixed with $5 \mu \mathrm{M}$ solution of RB, all in DMF. The sample solutions were then irradiated with $532 \mathrm{~nm}$ laser $\left(50 \mathrm{~mW} \mathrm{~cm}^{-2}\right)$ for particular intervals of time. The absorption and fluorescence $\left(\lambda_{\mathrm{ex}}=340 \mathrm{~nm}\right.$ for $\mathbf{1}$, and $350 \mathrm{~nm}$ for 2 ) spectra were recorded after each irradiation intervals. As control samples, a solution containing $\mathbf{1}$ or $\mathbf{2}$ with RB and $150 \mu \mathrm{M}$ aqueous solution of sodium azide was prepared, and the absorption and fluorescence spectra were recorded under identical photoirradiation conditions. 


\section{Results and Discussion}

We investigate ${ }^{1} \mathrm{O}_{2}$ sensing efficiencies of sensor $\mathbf{1}$ and compare it with that of $\mathbf{2}$, which is by analyzing the absorption and emission spectra of these two molecules as a function of time under photoirradiation of the sensitizer RB. Structures of $\mathbf{1}$ and $\mathbf{2}$ are shown in Figure 1B. Molecule $\mathbf{3}$, which is a control sample of $\mathbf{1}$, is synthesized for evaluating the fluorescence quantum yield of $\mathbf{1}$ and understanding the fluorescence enhancement factor of 1 upon reaction with ${ }^{1} \mathrm{O}_{2}$. The synthesis of 3 involves 1,8-diazabicyclo[5,4,0] undec-7-ene (DBU)catalyzed nucleophilic substitution reaction between 1-bromopropane and 7-amino,4-methyl coumarin. At first, we examined the absorption spectra of $\mathbf{1}-\mathbf{3}$, which is for understanding possible ground state interactions between the anthracene and coumarin portions in $\mathbf{1}$. Figure 1C shows the absorption spectra of 2 (a trace in red) and $\mathbf{3}$ (a trace in back). Figure 1D shows the sum absorption spectrum of $\mathbf{2}$ and $\mathbf{3}$ (a trace in red) and the absorption of $\mathbf{1}$ (a trace in black). In Figures $1 \mathrm{C}$ and $\mathrm{D}$, the absorption spectra were recorded for equal concentrations of individual samples dissolved in DMF. Although we expected complete overlap of the actual absorption spectrum of $\mathbf{1}$ with the sum absorption spectrum of $\mathbf{2}$ and $\mathbf{3}$, the actual spectrum shows an overall red-shift of ca $20 \mathrm{~nm}$, but without any changes in the anthracene vibrational band energies. The slight
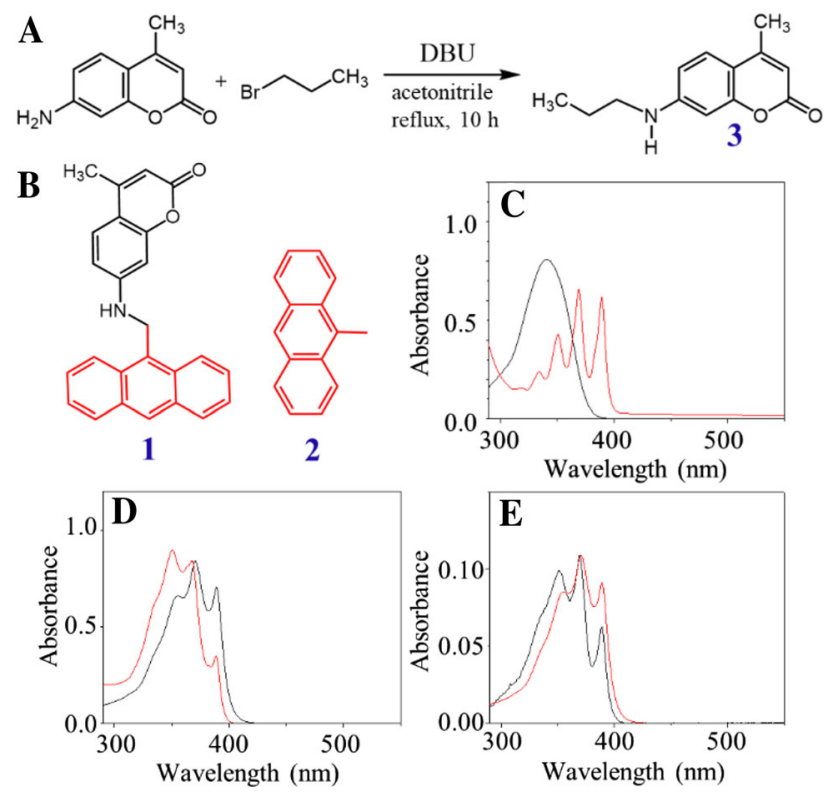

Figure 1. (A) The scheme of synthesis of model compound 3. (B) Structures of $\mathbf{1}$ and 2. (C) Absorption spectra of $\mathbf{2}$ (red trace) and $\mathbf{3}$ (black trace) in DMF. (D) Sum absorption spectra of $\mathbf{2}$ and $\mathbf{3}$ (red trace) and the absorption spectrum of $\mathbf{1}$ (black trace) in DMF. (E) Absorption spectrum of $\mathbf{1}$ in toluene (black trace) and DMF (red trace). red-shift is attributed to the ground state electronic interactions between the coumarin and anthracene portions in 1. Importantly, when compared with the 0-0 vibrational transition (ca $395 \mathrm{~nm}$ ) of 9-methylanthracene, it is amplified in $\mathbf{1}$.

As the intensity of lines is contributed by the FranckCondon factor, we assume that the higher intensity of $0-0$ transition in $\mathbf{1}$ originates from the short internuclear distance between the ground and excited electronic states of $\mathbf{1}$, when compared with $\mathbf{2}$, allowing an increased overlap between the ground and excited state vibrational wave functions in $\mathbf{1}$.

The focus of this research is to rationalize the role of substituents in anthracene on the rate of ${ }^{1} \mathrm{O}_{2}$ sensing using anthracene-based sensors. We evaluate this aim by systematically analyzing the absorption and fluorescence properties of $\mathbf{1}$ and $\mathbf{2}$ in presence of ${ }^{1} \mathrm{O}_{2}$. To evaluate the ${ }^{1} \mathrm{O}_{2}$ sensing efficiency of $\mathbf{1}$, a photooxidation reaction of $\mathbf{1}$ with ${ }^{1} \mathrm{O}_{2}$ generated by $\mathrm{RB}$ is carried out. A solution of $\mathbf{1}$ and RB (2:1 molar ratio) is prepared and irradiated with a $532 \mathrm{~nm}$ laser at $50 \mathrm{~mW} \mathrm{~cm}^{-2}$. Fluorescence spectra of the solution were recorded after every $5 \mathrm{~min}$ photosensitization (Figure 2A) for $60 \mathrm{~min}$. Approximately, a 20-fold increase in the fluorescence quantum efficiency of the sample was detected after $60 \mathrm{~min}$. This fluorescence enhancement is attributed to reaction of essentially nonfluorescent $\left(\Phi_{\mathrm{f}}=0.0032\right.$, estimated using coumarin 120 as the reference fluorophore) 1 with ${ }^{1} \mathrm{O}_{2}$ and the formation of a highly-fluorescent $\left(\Phi_{\mathrm{f}}=0.62\right.$, estimated using coumarin 120 as the reference fluorophore) 9,10endoperoxide of $\mathbf{1}$. As discussed in our previous work, ${ }^{28}$ the mechanism of fluorescence enhancement involves oxidation of the anthracene portion of $\mathbf{1}$ and blockage of intramolecular electron transfer from anthracene to coumarin (Figure 3). On the other hand, we did not observe any fluorescence enhancement for an equivalent solution supplemented with sodium azide (Figure 2B, a trace in red), which is an efficient ${ }^{1} \mathrm{O}_{2}$ scavenger. ${ }^{31}$ Thus, we confirm that the 20-fold fluorescence enhancement of $\mathbf{1}$ (Figure 2A) originates from oxidation of 1 by ${ }^{1} \mathrm{O}_{2}$.

The steps involved in the generation of ${ }^{1} \mathrm{O}_{2}$ by $\mathrm{RB}$ and the subsequent reactions of ${ }^{1} \mathrm{O}_{2}$ with $\mathbf{1}$ and $\mathbf{2}$ are presented in Figure 3. This manner of photosensitization and ${ }^{1} \mathrm{O}_{2}$ sensing processes was reported by Davidson and coworkers and considered to proceed through several steps as shown in Scheme $1 .^{33}$ Photoirradiation of the sensitizer RB activates it to the singlet excited state. Deactivation of the singlet excited state proceeds by non-radiative or radiative relaxation to the ground state or intersystem-crossing to the triplet state. The triplet RB sensitizes ground state molecular oxygen by triplet-triplet energy transfer and produces ${ }^{1} \mathrm{O}_{2}$. The 

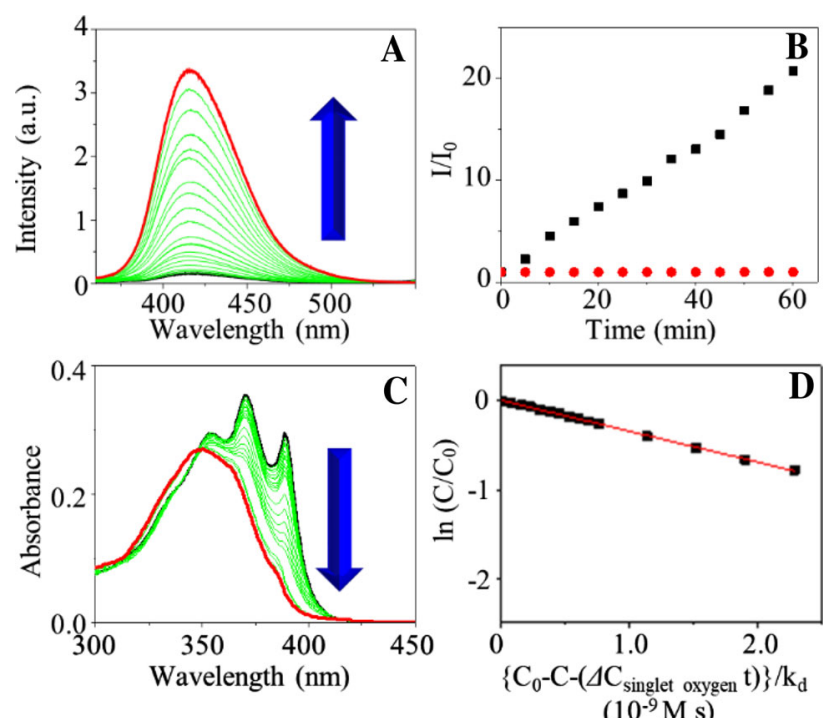

Figure 2. (A) Fluorescence $\left(\lambda_{\mathrm{ex}} 340 \mathrm{~nm}\right)$ and (C) absorption spectra of a solution of $1(10 \mu \mathrm{M})$ and $\mathrm{RB}(5 \mu \mathrm{M})$ in DMF, before and after every $5 \mathrm{~min}$ intervals of photoactivation at $532 \mathrm{~nm}\left(50 \mathrm{~mW} \mathrm{~cm}^{-2}\right)$. The fluorescence enhancement (ca 20-fold) is due to sensing of ${ }^{1} \mathrm{O}_{2}$ by 1 . (B) Time-traced relative fluorescence intensities of solutions of $\mathbf{1}(10 \mu \mathrm{M})$ and $\mathrm{RB}(5 \mu \mathrm{M})$ with (red traces) and without (black traces) $\mathrm{NaN}_{3}$ $(150 \mu \mathrm{M})$ in DMF. (D) The second order kinetic plot of photooxidation of $\mathbf{1}$ by ${ }^{1} \mathrm{O}_{2}$ constructed according to eq. 1 .

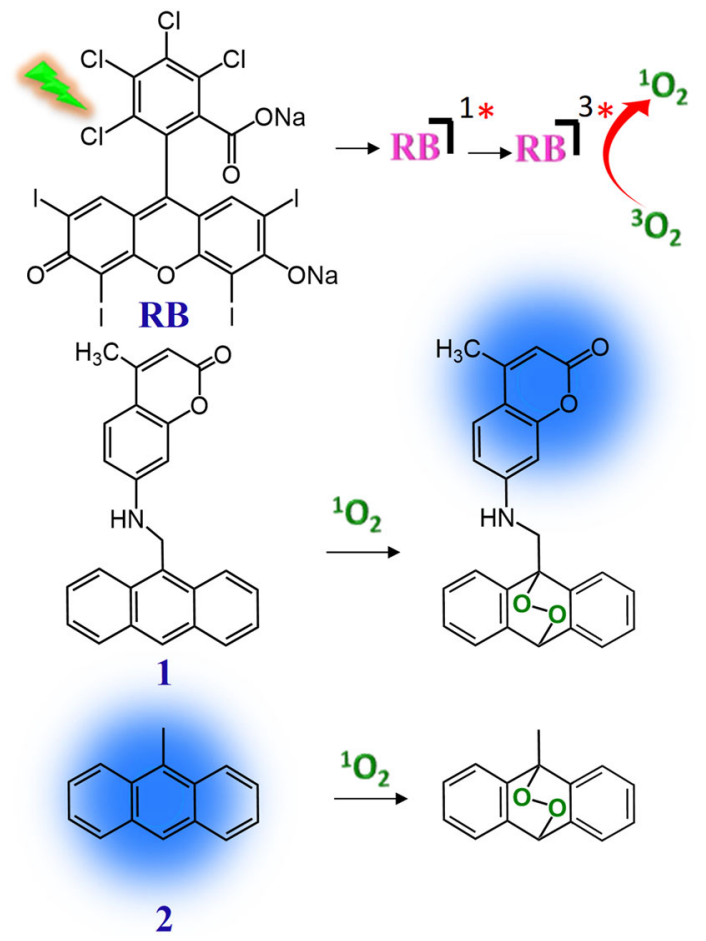

Figure 3. Schematic representation of the RB-sensitized generation of ${ }^{1} \mathrm{O}_{2}$, and photooxidation of $\mathbf{1}$ and 2 by ${ }^{1} \mathrm{O}_{2}$.

deactivation of ${ }^{1} \mathrm{O}_{2}$ proceeds by both relaxation with solvent molecules at the rate $\mathrm{k}_{\mathrm{d}}$ or reaction with $\mathbf{1}$ at rate $\mathrm{k}_{\mathrm{r}}$. The addition of ${ }^{1} \mathrm{O}_{2}$ to the anthracene part

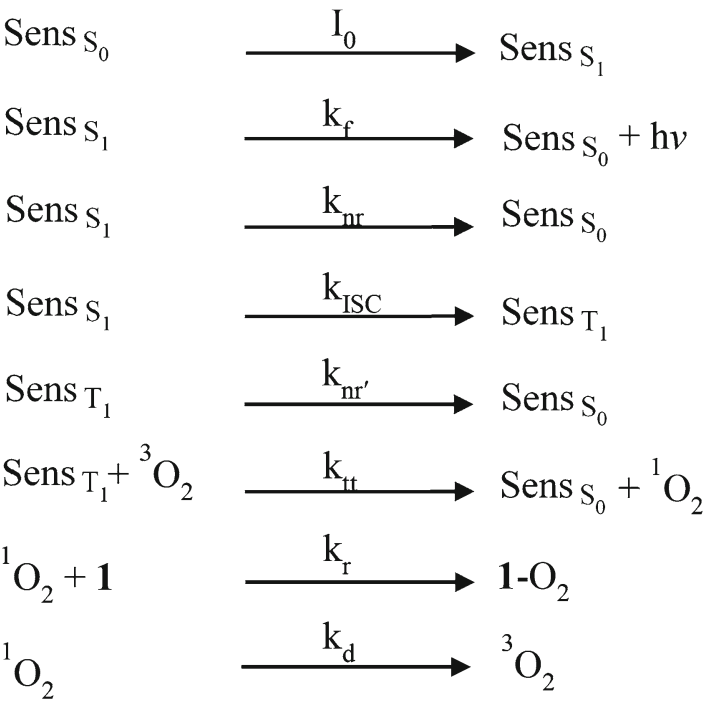

Scheme 1. Steps involved in the RB-sensitized ${ }^{1} \mathrm{O}_{2}$ generation and photooxidation of $\mathbf{1}$. Here, $\mathrm{k}_{\mathrm{f}}$ is the rate constant of radiative relaxation, $\mathrm{k}_{\mathrm{nr}}$ is the rate constant of non-radiative relaxation, $\mathrm{k}_{\mathrm{ISC}}$ is the rate constant of intersystem crossing, $\mathrm{k}_{\mathrm{nr}}$ is the rate constant of non-radiative relaxation of sensitizer from triplet excited state, $\mathrm{k}_{\mathrm{tt}}$ is the rate constant of photosensitization of molecular oxygen by triplet-triplet energy transfer, $\mathrm{k}_{\mathrm{r}}$ is the rate constant of reaction of ${ }^{1} \mathrm{O}_{2}$ with $\mathbf{1}$, and $\mathrm{k}_{\mathrm{d}}$ is the rate constant of non-radiative relaxation of ${ }^{1} \mathrm{O}_{2}$ by collision with solvent molecules.

in $\mathbf{1}$ involves an exciplex, which is followed by the formation of the 9,10-endoperoxide in a single step concerted mechanism. ${ }^{32}$ Due to the reaction of anthracene with ${ }^{1} \mathrm{O}_{2}$ and the formation of the endoperoxide, the intrinsic intramolecular electron transfer in $\mathbf{1}$ is blocked, uncaging the fluorescence of coumarin. This overall process leads to ${ }^{1} \mathrm{O}_{2}$ sensing using 1 . To understand the kinetics of sensing, the absorption the spectrum of $\mathbf{1}$ is recorded as a function of time under photoirradiation. As seen in Figure 2C, the absorbance of 1 in the 350 to $400 \mathrm{~nm}$ region, which is predominantly contributed by the anthracene part in $\mathbf{1}$, is monotonously decreased with time under photoactivation of RB.

As discussed in the case of fluorescence enhancement, the decrease of absorbance is due to oxidation of $\mathbf{1}$ by ${ }^{1} \mathrm{O}_{2}$. For the quantitative determination of the rate of sensing, we used the integral form of the second order rate equation (eq. 1), which is based on eq. 9 in ref. ${ }^{33}$.

$\ln \frac{\mathrm{C}}{\mathrm{C}_{0}}=-\mathrm{k} \frac{\left\{\mathrm{C}_{0}-\mathrm{C}-\left(\Delta \mathrm{C}_{\text {singlet oxygen }} \mathrm{t}\right)\right\}}{k_{d}}$,

where $\mathrm{C}_{0}$ and $\mathrm{C}$ are concentration (in $\mathrm{mol} \mathrm{L}^{-1}$ ) of the sensor ( $\mathbf{1}$ or $\mathbf{2}$ ) before and after photosensitization, respectively; $\Delta \mathrm{C}_{\text {singlet oxygen }}$ is the concentration $\left(8.86 \times 10^{-8} \mathrm{M} \mathrm{s}^{-1}\right)$ of ${ }^{1} \mathrm{O}_{2}$ produced by $\mathrm{RB}$ with time, 
which was calculated based on the number of photons $\left(1.16 \times 10^{17} \mathrm{~s}^{-1}\right)$ absorbed by RB per second and the number of ${ }^{1} \mathrm{O}_{2}$ produced; $\mathrm{k}$ is the second order rate constant which corresponds to the decrease of the substrate during the cycloaddition reaction; $\mathrm{k}_{\mathrm{d}}$ is the rate constant $\left(6.7 \times 10^{4} \mathrm{~s}^{-1}\right.$ in DMF) of deactivation of ${ }^{1} \mathrm{O}_{2}$ by the solvent; ${ }^{34}$ and $t$ is the time of photosensitization in seconds. Figure 2D shows the second order kinetic plot of the photooxidation of $\mathbf{1}$ by ${ }^{1} \mathrm{O}_{2}$. This plot is constructed based on eq. 1. Linear fitting of the data obtained from the plot of $\ln \frac{\mathrm{C}}{\mathrm{C}_{0}}$ vs $\frac{\left\{\mathrm{C}_{0}-\mathrm{C}-\left(\Delta \mathrm{C}_{\text {singlet oxygen }} \mathrm{t}\right)\right\}}{k_{d}}$ provides us with the rate of ${ }^{1} \mathrm{O}_{2}$ sensing by 1 at $3.4 \times 10^{8} \mathrm{M}^{-1} \mathrm{~s}^{-1}$.

To correlate between the role of the substituent on anthracene and ${ }^{1} \mathrm{O}_{2}$ sensing efficiency of substituted anthracenes, we evaluated the rate of reaction of $\mathbf{2}$ with ${ }^{1} \mathrm{O}_{2}$ and compared this rate with that of $\mathbf{1}$, both under identical experimental conditions and using the common photosensitizer RB. Upon continuous photoirradiation of $\mathrm{RB}$ at $532 \mathrm{~nm}\left(50 \mathrm{~mW} \mathrm{~cm}^{-2}\right)$ in a mixture of 2 and RB, as shown in Figure 4A and C, the fluorescence intensity and absorbance of $\mathbf{2}$ monotonously decreased due to oxidation of $\mathbf{2}$ by ${ }^{1} \mathrm{O}_{2}$ and the formation of a 9,10-endoperoxide (Figure 3 ). When compared with the 20-fold enhancement of fluorescence intensity (Figure 2A, 2B) for 1, which was after $60 \mathrm{~min}$ photoirradiation of $\mathrm{RB}$ with a $532 \mathrm{~nm}$ laser $\left(50 \mathrm{~mW} \mathrm{~cm}^{-2}\right)$, the fluorescence intensity of $\mathbf{2}$ is decreased by a factor of 20 (Figure 4A and B) in almost 10 min photoirradiation of RB with a $532 \mathrm{~nm}$ laser $\left(50 \mathrm{~mW} \mathrm{~cm}^{-2}\right)$. In other words, from fluorescence studies, we find that $\mathbf{2}$ reacts with ${ }^{1} \mathrm{O}_{2}$ at a rate higher than that by 1 . Like in the case of $\mathbf{1}$, we estimated the rate of reaction of 2 with ${ }^{1} \mathrm{O}_{2}$ using eq. 1 and by plotting $\ln \frac{\mathrm{C}}{\mathrm{C}_{0}}$ vs $\frac{\mathrm{C}_{0}-\mathrm{C}-\left(\mathrm{C}_{\text {singlet oxygen }} \mathrm{t}\right)}{\mathrm{Kk}_{\mathrm{d}}}$ Figure 4D). By analyzing this second order kinetic plot, we estimated the reaction rate of 2 at $3.3 \times 10^{9} \mathrm{M}^{-1} \mathrm{~s}^{-1}$, which is an order of magnitude greater than that of $\mathbf{1}$.

The electronic properties and steric aspects of the substituent on the sensor molecule play major roles on the reactivity of the sensor to ${ }^{1} \mathrm{O}_{2}$. We correlate the remarkable difference in the rates of ${ }^{1} \mathrm{O}_{2}$ sensing by $\mathbf{1}$ and $\mathbf{2}$ with the electronic interaction between anthracene and coumarin as well as the steric effect of coumarin. Based on DFT calculations and absorption spectral features (Figure 1), we consider that the anthracene moiety in $\mathbf{1}$ should be more electron rich than that in $\mathbf{2}$, which is due to the presence of aminocoumarin in $\mathbf{1}$. Indeed, with such an increase in the nucleophilicity of anthracene, one would expect an increased rate of reaction of $\mathbf{1}$ with the electrophilic ${ }^{1} \mathrm{O}_{2}$. However, the reactivity of 2 to ${ }^{1} \mathrm{O}_{2}$ is an order of magnitude greater than that of 1, suggesting that the coumarin substituent at the $9^{\text {th }}$
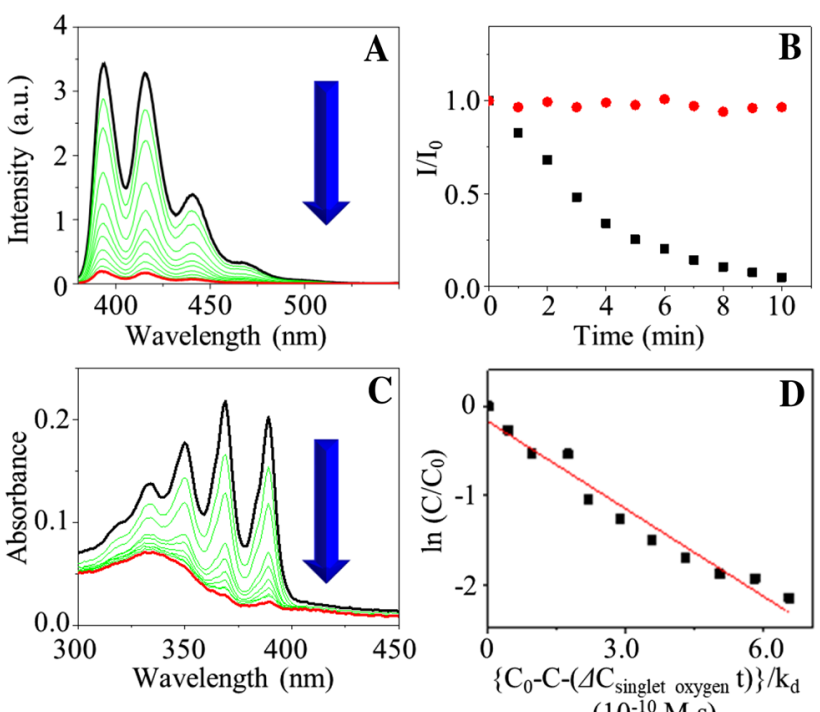

Figure 4. (A) Fluorescence spectra $\left(\lambda_{\text {ex }} 350 \mathrm{~nm}\right)$ of a solution of $2(10 \mu \mathrm{M})$ and $\mathrm{RB}(5 \mu \mathrm{M})$ in $\mathrm{DMF}$, before and after every 1 min interval of photoactivation $(532 \mathrm{~nm}$, $50 \mathrm{~mW} \mathrm{~cm}^{-2}$ ). (B) Time-traced relative fluorescence intensities of solutions of 2 and RB (2:1 molar ratio) with (red traces) and without (black traces) $\mathrm{NaN}_{3}(150 \mu \mathrm{M})$ in DMF. (C) The absorption spectra of a solution of $2(10 \mu \mathrm{M})$ and RB $(10 \mu \mathrm{M})$ in DMF before and after every $1 \mathrm{~min}$ interval of photoactivation $\left(532 \mathrm{~nm}, 50 \mathrm{~mW} \mathrm{~cm}^{-2}\right)$. (D) Second order kinetic plot of photooxidation of 2 by ${ }^{1} \mathrm{O}_{2}$ constructed according to eq. 1 .

position in $\mathbf{1}$ overshadows any increased nucleophilicity of anthracene and retards the reaction between 1 and ${ }^{1} \mathrm{O}_{2}$. In other words, the coumarin moiety in $\mathbf{1}$, when compared with a methyl group in $\mathbf{2}$, adversely affect the reactivity of ${ }^{1} \mathrm{O}_{2}$ to anthracene in $\mathbf{1}$. The role of coumarin on the low reactivity of $\mathbf{1}$ guides us to two possibilities truncated rate of formation of an exciplex between $\mathbf{1}$ and ${ }^{1} \mathrm{O}_{2}$, and/or poor reactivity of the exciplex. Although steric effect can be an important factor that retards the reaction rate, we continue to investigate the roles of the stability and reactivity of the exciplex between 1 and ${ }^{1} \mathrm{O}_{2}$ on the rate and efficiency of ${ }^{1} \mathrm{O}_{2}$ sensing.

\section{Conclusions}

The rate of ${ }^{1} \mathrm{O}_{2}$ sensing by a fluorogenic sensor (1), an anthracene-coumarin conjugate, was estimated and compared with that of 9-methylanthracene (2). Here, ${ }^{1} \mathrm{O}_{2}$ is generated by the selective $(532 \mathrm{~nm})$ excitation of Rose Bengal. While an enormous enhancement (for $\mathbf{1}$ ) or a substantial decrease (for 2) of fluorescence intensity allows us for the naked-eye detection of ${ }^{1} \mathrm{O}_{2}$, the sensing rates are precisely estimated from absorbencies of $\mathbf{1}$ or 2. In both cases, the anthracene part reacts with ${ }^{1} \mathrm{O}_{2}$ that the sensing rates are dictated by the reactivity of ${ }^{1} \mathrm{O}_{2}$ to the anthracene parts. When compared with 2, 1 shows 
an order of magnitude reduced reactivity to ${ }^{1} \mathrm{O}_{2}$. The difference between the reactivities of $\mathbf{1}$ and $\mathbf{2}$ to ${ }^{1} \mathrm{O}_{2}$ is correlated with the substituents (coumarin in $\mathbf{1}$ and a methyl group in 2) on anthracene. Although coumarin enhances the nucleophilicity of anthracene part in $\mathbf{1}$, it inserts steric effect to a greater extent than the methyl substituent in $\mathbf{2}$. In other words, the reduced reactivity of 1 to ${ }^{1} \mathrm{O}_{2}$ can be attributed to the steric effect induced by coumarin. Nonetheless, the role of an exciplex, which is the intermediate of the final product 9,10-endoperoxide, between $\mathbf{1}$ or $\mathbf{2}$ and ${ }^{1} \mathrm{O}_{2}$ on the ${ }^{1} \mathrm{O}_{2}$ sensing rate needs further attention.

\section{Acknowledgements}

D. S. acknowledges support under the English Program of Environmental Earth Science (EPEES) and a Scholarship by the Japan Student Services Organization (JASSO). V. B. acknowledges financial support (17H05243) from MEXT under the JSPS Grant-in-Aid for Scientific Research on Innovative Areas.

\section{References}

1. Prein M and Adam W 1996 The Schenck ene reaction: diastereoselective oxyfunctionalization with singlet oxygen in synthetic applications Angew. Chem. 35477

2. Ghogare A A and Greer A 2016 Using singlet oxygen to synthesize natural products and drugs Chem. Rev. 116 9994

3. Ohloff G 1975 Singlet oxygen: A reagent in organic synthesis Pure Appl. Chem. $\mathbf{4 3} 481$

4. Dougherty T J, Grindey G B, Fiel R, Weishaupt K R and Boyle D G 1975 Photoradiation therapy. II. Cure of animal tumors with hematoporphyrin and light $J$. Natl. Cancer Inst. $\mathbf{5 5} 115$

5. Dougherty T J 1984 Photodynamic therapy (PDT) of malignant tumors Crit. Rev. Oncol. Hematol. 283

6. Dolmans D E, Fukumura D and Jain R K 2003 Photodynamic therapy for cancer Nat. Rev. Cancer 3380

7. Kim H, Kim W, Mackeyev Y, Lee G S, Kim H J, Tachikawa T, Hong S, Lee S, Kim J, Wilson L J and Majima T 2012 Selective oxidative degradation of organic pollutants by singlet oxygen-mediated photosensitization: tin porphyrin versus $\mathrm{C}_{60}$ aminofullerene systems Environ. Sci. Technol. 46960

8. Phonsy P D, Anju S G, Jyothi K, Yesodharan S and Yesodharan E P 2015 Semiconductor Mediated Photocatalytic Degradation of Plastics and Recalcitrant Organic Pollutants in Water: Effect of Additives and Fate of Insitu Formed $\mathrm{H}_{2} \mathrm{O}_{2} J$. Adv. Oxid. Technol. 1885

9. Gryglik D, Miller J S and Ledakowicz S 2007 Singlet molecular oxygen application for 2-chlorophenol removal J. Hazard. Mater. 146502

10. D'Autréaux B and Toledano M B 2007 ROS as signalling molecules: mechanisms that generate specificity in ROS homeostasis Nat. Rev. Mol. Cell Biol. 8813
11. Ray P D, Huang B W and Tsuji Y 2012 Reactive oxygen species (ROS) homeostasis and redox regulation in cellular signaling Cell Signal. 24981

12. Choi M H, Lee I K, Kim G W, Kim B U, Han Y H, Yu D Y, Park H S, Kim K Y, Lee J S, Choi C and Bae Y S 2005 Regulation of PDGF signalling and vascular remodelling by peroxiredoxin II Nature $\mathbf{4 3 5} 347$

13. Petrou A L and Terzidaki A 2017 A meta-analysis and review examining a possible role for oxidative stress and singlet oxygen in diverse diseases Biochem. J. 474 2713

14. Ames B N, Shigenaga M K and Hagen T M 1993 Oxidants, antioxidants, and the degenerative diseases of aging Proc. Natl. Acad. Sci. U. S. A. 907915

15. Smith M A, Rottkamp C A, Nunomura A, Raina A K and Perry G 2000 Oxidative stress in Alzheimer's disease Biochim. Biophys. Acta Mol. Basis Dis. 1502139

16. Davies M J 2003 Singlet oxygen-mediated damage to proteins and its consequences Biochem. Biophys. Res. Commun. 305761

17. Sies H and Menck C F 1992 Singlet oxygen induced DNA damage Mutat. Res. 275367

18. Laloi C and Havaux M 2015 Key players of singlet oxygen-induced cell death in plants Front. Plant Sci. 6 39

19. DeRosa M C and Crutchley R J 2002 Photosensitized singlet oxygen and its applications Coord. Chem. Rev. 233351

20. Lion Y, Delmelle M and Van de Vorst A 1976 New method of detecting singlet oxygen production Nature 263442

21. Jiménez-Banzo A, Ragas X, Kapusta $P$ and Nonell S 2008 Time-resolved methods in biophysics. 7. Photon counting vs. analog time-resolved singlet oxygen phosphorescence detection Photochem. Photobiol. Sci. 7 1003

22. Niedre M, Patterson M S and Wilson B C 2002 Direct near-infrared luminescence detection of singlet oxygen generated by photodynamic therapy in cells in vitro and tissues in vivo J. Photochem. Photobiol. 75 382

23. Oelckers S, Ziegler T, Michler I and Röder B 1999 Timeresolved detection of singlet oxygen luminescence in red-cell ghost suspensions: concerning a signal component that can be attributed to ${ }^{1} \mathrm{O}_{2}$ luminescence from the inside of a native membrane J. Photochem. Photobiol. B Biol. 53121

24. Tanaka K, Miura T, Umezawa N, Urano Y, Kikuchi K, Higuchi T and Nagano T 2001 Rational design of fluorescein-based fluorescence probes. Mechanismbased design of a maximum fluorescence probe for singlet oxygen J. Am. Chem. Soc. 1232530

25. Kim S, Tachikawa T, Fujitsuka M and Majima T 2014 Far-red fluorescence probe for monitoring singlet oxygen during photodynamic therapy J. Am. Chem. Soc. 136 11707

26. Pedersen S K, Holmehave J, Blaikie F H, Gollmer A, Breitenbach T, Jensen H H and Ogilby P R 2014 Aarhus sensor green: a fluorescent probe for singlet oxygen $J$. Org. Chem. 793079

27. Flors C, Fryer M J, Waring J, Reeder B, Bechtold U, Mullineaux P M, Nonell S, Wilson M T and Baker N R 
2006 Imaging the production of singlet oxygen in vivo using a new fluorescent sensor, Singlet Oxygen Sensor Green $^{\circledR}$ J. Exp. Bot. 571725

28. Kohara R, Yuyama K I, Shigeri Y and Biju V 2017 BlueEmitting electron-donor/acceptor dyads for naked-eye fluorescence detection of singlet oxygen ChemPhotoChem 1299

29. Song B, Wang G, Tan M and Yuan J 2006 A europium (III) complex as an efficient singlet oxygen luminescence probe J. Am. Chem. Soc. 12813442

30. Zoltan T, Vargas F and Izzo C 2007 UV-Vis spectrophotometrical and analytical methodology for the determination of singlet oxygen in new antibacterials drugs Anal. Chem. Insights 2111
31. Li M Y, Cline C S, Koker E B, Carmichael H H, Chignell C F and Bilski P 2001 Quenching of singlet molecular oxygen $\left({ }^{1} \mathrm{O}_{2}\right)$ by azide anion in solvent mixtures Photochem. Photobiol. 74760

32. Aubry J M, Pierlot C, Rigaudy J and Schmidt R 2003 Reversible binding of oxygen to aromatic compounds Acc. Chem. Res. 36668

33. Davidson R S and Trethewey K R 1977 Factors affecting dye-sensitised photo-oxygenation reactions J. Chem. Soc., Perkin Trans. 22169

34. Wilkinson F and Brummer J G 1981 Rate constants for the decay and reactions of the lowest electronically excited singlet state of molecular oxygen in solution $J$. Phys. Chem. Ref. Data 10809 